\title{
Relación entre los perfiles de dominancia cerebral de los estudiantes de primero, quinto y décimo semestres delPrograma de Bacteriología y Laboratorio Clínico de la Universidad Colegio Mayor de Cundinamarca
}

\author{
Bertha Marlén Velásquez Burgos ${ }^{1}$, Nahyr Remolina de Cleves' \\ María Graciela Calle M'
}

1. Universidad Colegio Mayor de Cundinamarca, Bogotá - Colombia.

Correspondencia: bemar5@yahoo.es

Recibido 04-02-08 / Aceptado 19-04-08

\begin{abstract}
Resumen
El presente artículo sintetiza los resultados obtenidos en el proyecto de investigación sobre la relación entre los perfiles de dominancia cerebral de los estudiantes de primero, quinto y décimo semestres del Programa de Bacteriología y Laboratorio Clínico de la Universidad Colegio Mayor de Cundinamarca de Bogotá, Colombia. Los estudiantes presentan un desarrollo apreciable en el cuadrante A; es decir, tienen mayor dominancia en el cuadrante cortical izquierdo. No obstante, se observa poca dominancia en el cuadrante cortical derecho D, lo cual supone que estos estudiantes presentan un estilo de pensamiento lógico, cualitativo, analítico, crítico, matemático y se basan en hechos concretos. Sin embargo, la visión holística, la imaginación, la creatividad, la prospectiva y la heurística indispensables en la óptima potenciación de las capacidades del cerebro total no son dominantes. Por otra parte, los resultados evidencian cambios poco significativos entre los estudiantes de primero, quinto y décimo semestres en cuanto a sus puntuaciones de dominancia cerebral o estilos de pensamiento. Diferentes fuentes teóricas han señalado que múltiples capacidades cognoscitivas y conductuales tienen un origen génico.

Palabras clave: cerebro total, dominancia cerebral, formas de pensamiento, hemisferio cerebral, neocorteza, sistema límbico.
\end{abstract}

\footnotetext{
Abstract

Relation among the profiles of cerebral dominance of first, fifth, and tenth semester students of the bacteriology program and clinical laboratory of the University Colegio Mayor de Cundinamarca

This article synthesizes the results of the investigation on the relation between the profiles of cerebral dominance of the students of first, fifth, and tenth semesters of the bacteriology program and clinical laboratory of the University Colegio Mayor de Cundinamarca in Bogota, Colombia. The students display an appreciable development in quadrant A; that is to say, they have greater dominance in the left cortical quadrant. However, little dominance in the right cortical quadrant $D$ is observed, which supposes that these students have a style of
} 
logical, qualitative, analytical, critical, mathematical thought and they are based on concrete facts. Nevertheless, their holistic vision, imagination, creativity, perspective, and heuristic necessary in the optimization of the capacities of the whole brain are not dominant. On the other hand, the results showed little changes among the students of first, fifth, and tenth semesters as far as their scores of cerebral dominance or styles of thought. Different theoretical sources have suggested multiple cognitive and behavioral capacities originate in the genes.

Key words: cerebral dominance, cerebral hemisphere, forms of thought, limbic system, neocortex, whole brain.

\section{Introducción}

De acuerdo con las investigaciones científicas producidas en la década conocida como "década del cerebro" (años 90s), hoy se dispone de conocimientos más amplios y precisos sobre el funcionamiento del mismo y sus admirables potencialidades. En este sentido, es significativo dentro del ámbito educativo reconocer algunas características relevantes del modelo del Cerebro Total investigado por Herrmann (1) quien realizó sus estudios basado en los de Sperry (2) y MacLean (3) quienes lo condujeron a replantear el funcionamiento del cerebro integrando la neocorteza (hemisferios derecho e izquierdo) con el sistema límbico. Esta integración la concibe como una totalidad orgánica dividida en cuatro cuadrantes o áreas, todas ellas directa o indirectamente conectadas entre sí por el cuerpo calloso y otras comisuras.

Los cuadrantes llamados A, B, C y D corresponden a cuatro modos determinados, distintos e independientes de procesamiento diferencial de información, identificados especialmente por el método estadístico de conglomerados (clusters) y con el apoyo empírico de multitud de datos rigurosamente procesados. Los cuatro cuadrantes representan formas distintas de operar, pensar, crear, aprender $y$, en suma, de convivir con el mundo, aun cuando se admite que el cerebro funciona como una totalidad integrada.

Cada uno de los cuadrantes realiza funciones específicas. El cuadrante superior izquierdo denominado cortical izquierdo (cuadrante A) se especializa en el pensamiento lógico, cualitativo, analítico, crítico, matemático y basado en hechos concretos. El cuadrante inferior izquierdo, límbico izquierdo (cuadrante B), se caracteriza por un estilo de pensamiento secuencial, organizado, planificado, detallado y controlado. El cuadrante inferior derecho: límbico derecho (cuadrante C) se relaciona con el pensamiento emocional, sensorial, humanístico, interpersonal, simbólico y espiritual. Finalmente, el cuadrante superior derecho, cortical derecho (cuadrante D), se destaca por un modo de pensamiento conceptual, holístico, integrador, global, sintético, creativo, artístico, espacial, visual y metafórico.

Los cuatro cuadrantes antes señalados se complementan y forman, a su vez, cuatro nuevas modalidades de pensamiento: (1) realista y del sentido común formado por los cuadrantes A y B (hemisferio izquierdo); (2) idealista y kinestésico, constituido por los cuadrantes C y D (hemisferio derecho); (3) pragmático o cerebral, conformado por los cuadrantes A y D; (4) instintivo y visceral formado por los cuadrantes B y C (sistema límbico).

Herrmann SL llega a la validación de su modelo a partir del análisis factorial de las respuestas de un cuestionario aplicado a una muestra de más de 100.000 ciudadanos norteamericanos (1). El cuestionario en mención contiene ítems que representan las diferentes funciones cerebrales que usualmente utilizan los individuos en situaciones académicas, laborales, de recreación y de la vida diaria. En cada caso, se le pide al sujeto indicar su preferencia por tal o cual situación, con el objeto de identificar cuál es la tendencia de su dominancia respecto a cada cuadrante.

Teniendo en cuenta los resultados de las investigaciones realizadas sobre el tema, donde se resalta la importancia que tiene para los docentes conocer las potencialidades de sus estudiantes con el fin de direccionar el proceso de la enseńanza y del aprendizaje (1-7), se propusos analizar el perfil de dominancia cerebral de los estudiantes de primero, quinto y décimo semestres, para luego relacionar los resultados y comparar si el proceso de formación ha incidido en el desarrollo del cerebro total de los mismos. 


\section{Materiales y métodos}

De acuerdo con los objetivos de la investigación se adoptó un método descriptivo, por cuanto específica las características del perfil de dominancia cerebral o estilos de pensamiento de los estudiantes, y comparativo porque contrasta las categorías relacionadas con los cuatro cuadrantes de los estudiantes de I, Vy X semestres de Bacteriología de la Universidad Colegio Mayor de Cundinamarca. Se seleccionaron 30 estudiantes de manera aleatoria, de acuerdo con la aceptación y disponibilidad de cada uno de los semestres.

Para evaluar el grado en que los estudiantes procesan los cuatro cuadrantes del modelo de cerebro total propuesto por Ned Herrmann en 1989 (8), se utilizó un formato de encuesta elaborado por Gardié denominado Diagnóstico Integral de Dominancia Cerebral (DIDC) (9). La aplicación del instrumento valora la preferencia en la utilización de los cuadrantes, lo que da lugar a perfiles de dominancia que se manifiestan desde la dominancia simple (preferencia por un único estilo de pensamiento) hasta la cuádruple y las combinaciones posibles que involucran la dominancia doble y triple. La aplicación del instrumento es realizada de manera individual en sus ambientes naturales de trabajo, (aula de clase o laboratorio), fue diligenciado en un lapso de 20 a 30 minutos.

El DIDC consta de una parte introductoria en la que el estudiante consigna sus datos bibliográficos y 48 ítems distribuidos en las siguientes secciones: Parte I, en una escala tipo Likert se presentan 20 situaciones relacionadas con actividades del trabajo y de la vida diaria, con una escala de cinco a cero. Parte II, constituida por ocho ítems, referidos a conductas y creencias propias de nuestra personalidad, se deben marcar solamente cuatro ítems, aquellos que le parezcan más acertados. Parte III, conformada por ocho ítems relacionados con aspectos de gran interés para el bienestar y mejor calidad de vida de la sociedad. Se deben seleccionar solamente cuatro ítems, aquellos que se valoren como los más relevantes. Parte IV, se ofrecen por separado seis pares de adjetivos para que sea seleccionado en cada par aquél que mejor describa la personalidad de quien responde. La evaluación del instrumento consiste en determinar el grado de preferencia que se le asigna a los cuadrantes A, B, C y D. Para el procesamiento de la información se utilizaron tablas de distribución de frecuencias y categorización de respuestas elaboradas a través de matrices.

\section{Análisis}

El procesamiento de los datos se realizó teniendo en cuenta el modelo de Ned Herrmann (1), la encuesta y escala de medición propuesta y empleada por Gardié (9), Tabla 1.

\section{Resultados}

En las Tablas 2-7 se muestran los resultados de los perfiles y tipos de dominancia y las frecuencias de tipo de dominancia de cada uno de los semestres incluidos en el estudio. En las Figuras 1-3 se presentan los porcentajes de dominancia por cuadrante.

\section{Caracterización de los perfiles resultantes}

2-1-2-2 Dominancia simple: este perfil indica una clara preferencia por el cuadrante B (límbico izquierdo); se caracteriza por imponer la razón sobre la realidad, rechazan la ambigüedad, son organizados y se proyectan hacia la acción; desconfían de las emociones y la intuición; controlan sus ambientes y su propia personalidad; se proponen realizar sus tareas de manera correcta y a tiempo; se distinguen por focalizar un solo aspecto a la vez, mantener el sentido de previsibilidad y seguridad.

Tabla 1. Clases de dominancia y perfil según rango propuesto.

\begin{tabular}{llc}
\hline \multicolumn{1}{c}{ Rango en puntos } & \multicolumn{1}{c}{ Dominancia } & Perfil \\
$67-100$ & Primaria & 1 \\
$34-66$ & $\begin{array}{l}\text { Secundaria } \\
\text { Ni dominancia ni rechazo }\end{array}$ & 2 \\
$0-33$ & $\begin{array}{l}\text { Terciaria } \\
\text { Rechazo }\end{array}$ & 3 \\
\hline
\end{tabular}


Tabla 2. Perfiles resultantes y tipo de dominancia de I semestre.

\begin{tabular}{cccc}
\hline $\begin{array}{c}\text { PERFILES } \\
\text { RESULTANTES }\end{array}$ & TIPO DE DOMINANCIA & $\begin{array}{c}\text { FRECUENCIA } \\
\text { ABSOLUTA }\end{array}$ & $\begin{array}{c}\text { FRECUENCIA } \\
\text { RELATIVA }\end{array}$ \\
\hline $2-1-2-2$ & Simple & 6 & $20 \%$ \\
$2-1-1-2$ & Doble & 3 & $10 \%$ \\
$1-2-2-2$ & Simple & 6 & $20 \%$ \\
$2-2-2-2$ & Sin dominancia & 2 & $7 \%$ \\
$1-2-1-1$ & Triple & 1 & $3 \%$ \\
$1-2-1-2$ & Doble & 3 & $10 \%$ \\
$2-2-2-1$ & Simple & 3 & $10 \%$ \\
$1-1-2-2$ & Doble & 3 & $10 \%$ \\
$1-1-1-2$ & Triple & 1 & $3 \%$ \\
$2-2-1-2$ & Simple & 1 & $3 \%$ \\
$2-2-1-1$ & Doble & 1 & $3 \%$ \\
Total & & 30 & $100 \%$ \\
\hline
\end{tabular}

Les falta: apertura, fantasía y visión global; no saben qué hacer frente a un imprevisto, ni resumir un texto, tampoco describir una situación determinada.

2-1-1-2 Dominancia doble: los individuos con una preferencia primaria por las características de los cuadrantes B y C (límbico izquierdo y límbico derecho), imponen la razón sobre la realidad; desconfían de las emociones y la intuición; controlan sus ambientes y su propia personalidad; son organizados; se proponen realizar las tareas de manera correcta y a tiempo; se distinguen por focalizar un solo aspecto a la vez; y mantener el sentido de previsibilidad y seguridad. Les falta: apertura, fantasía y visión global; no saben qué hacer frente a un imprevisto, ni resumir un texto, como tampoco describir una situación determinada.

(C) Rechazan la ambigüedad; son organizados y se proyectan hacia la acción; son receptivos, sensitivos y conciliatorios; su sensibilidad es importante para ayudar a otros a crecer y a cambiar; son empáticos y sociables; se distinguen por su capacidad de comunicación y de interacción social; son personas espirituales. A los individuos que tienen desarrollado el límbico derecho les falta: orden, rigor, conocimientos precisos, saber escuchar, control y dominio de si mismo, organización; demuestran poca autonomía y perspectiva frente a la opinión ajena.

1-2-2-2 Dominancia simple: son individuos que demuestran una clara preferencia por las características del cuadrante A (cortical izquierdo); se caracterizan por su facilidad para resolver problemas; dan importancia a la argumentación y la crítica sobre la experiencia personal y a los hechos sobre la intuición; demuestran ser individuos fríos y arrogantes; sus soluciones, aunque lógicas, resultan demasiado lineales y poco creativas. Les falta: imaginación, creatividad, tienen pocas ideas personales y no expresan su sensibilidad; demuestran pocas aptitudes para el arte; son demasiado individualistas.

2-2-2-2 Sin dominancia: en este perfil no existe dominancia; es un perfil promedio indicador de la existencia de un desarrollo intermedio de los cuatro cuadrantes, siendo necesarios algunos procesos cognitivos y metodológicos para potenciar el cerebro total.

1-2-1-1 Dominancia triple: se refiere a ciertos perfiles que tienen un solo cuadrante que no es primario. Los individuos con este tipo de perfil tienen habilidades lingüísticas, por cuanto les es fácil interactuar libremente con los otros cuadrantes. La desventaja de los perfiles de 
triple dominancia es que pueden llevar más tiempo para madurar, debido a las mismas posiciones opuestas que se van a encontrar entre los cuadrantes, tal y como sucede con los cuadrantes diagonalmente opuestos.

1-2-1-2 Dominancia doble: son individuos que demuestran una clara preferencia por las características del cuadrante A (cortical izquierdo) y el cuadrante C ; se caracterizan por su facilidad para resolver problemas; dan importancia a la argumentación y la crítica sobre la experiencia personal y a los hechos sobre la intuición; demuestran ser individuos fríos y arrogantes; sus soluciones, aunque lógicas, resultan demasiado lineales y poco creativas. Les falta: imaginación, creatividad, tienen pocas ideas personales y no expresan su sensibilidad; demuestran pocas aptitudes para el arte; son demasiado individualistas.

(C) Rechazan la ambigüedad; son organizados y se proyectan hacia la acción; son receptivos, sensitivos y conciliatorios; su sensibilidad es importante para ayudar a otros a crecer y a cambiar; son empáticos y sociables; se distinguen por su capacidad de comunicación y de interacción social; son personas espirituales. A los individuos que tienen desarrollado el límbico derecho les falta: orden, rigor, conocimientos precisos, saber escuchar, control y dominio de si mismo, organización; demuestran poca autonomía y perspectiva frente a la opinión ajena.

2-2-2-1 Dominancia simple: este perfil presenta una preferencia por el cuadrante D (cortical derecho); los individuos se caracterizan por ser innovadores, creativos y visionarios; hacen uso de las metáforas, del pensamiento analógico y la representación; rechazan lo tradicional y las estructuras rígidas; son lúdicos, fantasiosos e imaginativos por naturaleza. Les falta organización, estructura, claridad, rigor, lógica y método.

1-1-2-2 Dominancia doble: este perfil presenta preferencia por el cuadrante A (cortical izquierdo) y B (límbico izquierdo) ; los individuos se caracterizan por su facilidad para resolver problemas; dan importancia a la argumentación y la crítica sobre la experiencia personal y a los hechos sobre la intuición; demuestran ser individuos fríos y arrogantes; sus soluciones, aunque lógicas, resultan demasiado lineales y poco creativas. Les falta: imaginación, creatividad, tienen pocas ideas personales y no expresan su sensibilidad; demuestran pocas aptitudes para el arte; son demasiado individualistas.
(B) se caracteriza por imponer la razón sobre la realidad, rechazan la ambigüedad, son organizados y se proyectan hacia la acción; desconfían de las emociones y la intuición; controlan sus ambientes y su propia personalidad; se proponen realizar sus tareas de manera correcta y a tiempo; se distinguen por focalizar un solo aspecto a la vez, mantener el sentido de previsibilidad y seguridad. Les falta: apertura, fantasía y visión global; no saben qué hacer frente a un imprevisto, ni resumir un texto, tampoco describir una situación determinada.

1-1-1-2 Dominancia triple: dominancia primaria en los cuadrantes cortical izquierdo (A), límbico izquierdo (B), límbico derecho (C) y dominancia secundaria en el cortical derecho(D) ); se caracterizan por su facilidad para resolver problemas; dan importancia a la argumentación y la crítica sobre la experiencia personal y a los hechos sobre la intuición; son individuos fríos y arrogantes; sus soluciones, aunque lógicas, resultan demasiado lineales y poco creativas.Les falta: imaginación, creatividad, tienen pocas ideas personales y no expresan su sensibilidad; tienen pocas aptitudes para el arte, son demasiado individualistas.

(B) En general, imponen la razón sobre la realidad; desconfían de las emociones y la intuición; controlan sus ambientes y su propia personalidad; son organizados; se proponen realizar sus tareas de manera correcta y a tiempo; se distinguen por focalizar un solo aspecto a la vez, así como por mantener el sentido de previsibilidad y seguridad. Les falta: apertura, fantasía y visión global; no saben qué hacer frente a un imprevisto; no saben resumir un texto, ni describir una situación determinada.

(C) Rechazan la ambigüedad; son organizados y se proyectan hacia la acción; son receptivos, sensitivos y conciliatorios; su sensibilidad es importante para ayudar a otros a crecer y a cambiar; son empáticos y sociables; se distinguen por su capacidad de comunicación y de interacción social; son personas espirituales. A los individuos que tienen desarrollado el límbico derecho les falta: orden, rigor, conocimientos precisos, saber escuchar, control y dominio de si mismo, organización; demuestran poca autonomía y perspectiva frente a la opinión ajena.

2-2-1-2 Dominancia simple: estos individuos presentan dominancia primaria en el cuadrante $\mathrm{C}$ (límbico derecho) y dominancia secundaria en el cortical 
Tabla 3. Frecuencias tipos de dominancia de I semestre.

\begin{tabular}{ccc}
\hline Dominancia & Frecuencia absoluta & Frecuencia relativa \\
Simple & 16 & $53 \%$ \\
Doble & 10 & $33 \%$ \\
Triple & 2 & $7 \%$ \\
Sin dominancia & 2 & $7 \%$ \\
Total & 30 & $100 \%$ \\
\hline
\end{tabular}

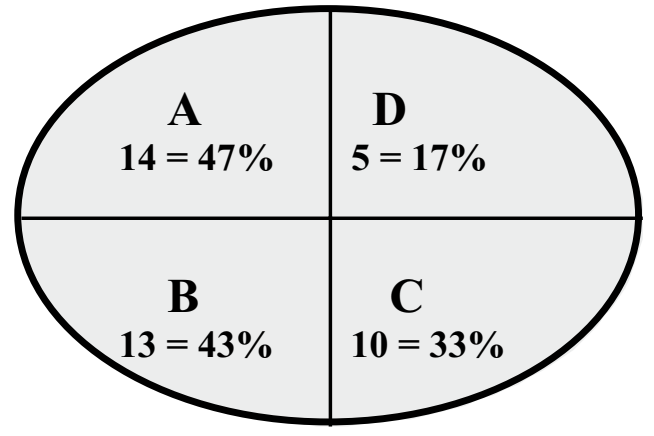

Figura 1. Dominancia por cuadrante I semestre izquierdo, límbico izquierdo y cortical derecho. Rechazan la ambigüedad; son organizados y se proyectan hacia la acción; son receptivos, sensitivos y conciliatorios; su sensibilidad es importante para ayudar a otros a crecer y a cambiar; son empáticos y sociables; se distinguen por su capacidad de comunicación y de interacción social; son personas espirituales. A los individuos que tienen desarrollado el límbico derecho les falta: orden, rigor, conocimientos precisos, saber escuchar, control y dominio de si mismo, organización; demuestran poca autonomía y perspectiva frente a la opinión ajena.

Tabla 4. Perfiles resultantes y tipo de dominancia $\vee$ semestre

\begin{tabular}{cccc}
\hline PERFILES RESULTANTES & TIPO DE DOMINANCIA & $\begin{array}{c}\text { FRECUENCIA } \\
\text { ABSOLUTA }\end{array}$ & $\begin{array}{c}\text { FRECUENCIA } \\
\text { RELATIVA }\end{array}$ \\
$2-2-2-2$ & Sin dominancia & 5 & $17 \%$ \\
$1-2-2-2$ & Simple & 4 & $13 \%$ \\
$1-1-2-2$ & Doble & 3 & $10 \%$ \\
$2-2-2-1$ & Simple & 5 & $17 \%$ \\
$2-1-1-2$ & Doble & 1 & $3 \%$ \\
$2-1-2-2$ & Simple & 4 & $13 \%$ \\
$1-2-1-2$ & Doble & 2 & $7 \%$ \\
$2-1-2-3$ & Simple & 2 & $7 \%$ \\
$1-2-3-2$ & Simple & 1 & $3 \%$ \\
$2-2-1-1$ & Doble & 1 & $3 \%$ \\
$2-1-1-1$ & Triple & 1 & $3 \%$ \\
$2-1-2-1$ & Doble & 1 & $3 \%$ \\
Total & & 30 & $100 \%$ \\
\hline
\end{tabular}


2-2-1-1 Dominancia doble: dominancia primaria en los cuadrantes límbico derecho(C), cortical derecho (D) y dominancia secundaria en los cuadrantes cortical izquierdo, límbico izquierdo. (C) Rechazan la ambigüedad; son organizados y se proyectan hacia la acción; son receptivos, sensitivos y conciliatorios; su sensibilidad es importante para ayudar a otros a crecer y a cambiar; son empáticos y sociables; se distinguen por su capacidad de comunicación y de interacción social; son personas espirituales. A los individuos que tienen desarrollado el límbico derecho les falta: orden, rigor, conocimientos precisos, saber escuchar, control y dominio de si mismo, organización; demuestran poca autonomía y perspectiva frente a la opinión ajena. (D) los individuos se caracterizan por ser innovadores, creativos y visionarios; hacen uso de las metáforas, del pensamiento analógico y la representación; rechazan lo tradicional y las estructuras rígidas; son lúdicos, fantasiosos e imaginativos por naturaleza. Les falta organización, estructura, claridad, rigor, lógica y método. (10), Tablas 3 y 4.

\section{Caracterización de los perfiles resultantes}

2-2-2-2 Sin dominancia: es un perfil promedio que indica la existencia de un desarrollo intermedio de los cuatro cuadrantes, siendo necesarios algunos procesos cognitivos y metodológicos para potenciar el cerebro total.

1-2-2-2 Dominancia simple: indica una clara preferencia por el cuadrante A ( Cortical izquierdo) se caracterizan por su facilidad para resolver problemas; dan importancia a la argumentación y la crítica sobre la experiencia personal y a los hechos sobre la intuición; son individuos fríos y arrogantes; sus soluciones, aunque lógicas, resultan demasiado lineales y poco creativas. Les falta: imaginación, creatividad, tienen pocas ideas personales y no expresan su sensibilidad; tienen pocas aptitudes para el arte, son demasiado individualistas.

1-1-2-2 Dominancia doble: son individuos que demuestran una clara preferencia por las características del cuadrante A y B (cortical izquierdo y límbico izquierdo); se caracterizan por su facilidad para resolver problemas; dan importancia a la argumentación y la crítica sobre la experiencia personal y a los hechos sobre la intuición; son individuos fríos y arrogantes; sus soluciones, aunque lógicas, resultan demasiado lineales y poco creativas. Les falta: imaginación, creatividad, tienen pocas ideas personales y no expresan su sensibilidad; tienen pocas aptitudes para el arte, son demasiado individualistas.

(B) En general, imponen la razón sobre la realidad; desconfían de las emociones y la intuición; controlan sus ambientes y su propia personalidad; son organizados; se proponen realizar sus tareas de manera correcta y a tiempo; se distinguen por focalizar un solo aspecto a la vez, así como por mantener el sentido de previsibilidad y seguridad. Les falta: apertura, fantasía y visión global; no saben qué hacer frente a un imprevisto; no saben resumir un texto, ni describir una situación determinada.

2-2-2-1 Dominancia simple: los individuos con una preferencia primaria, sólo en el cuadrante D (cortical derecho), se caracterizan por ser innovadores, creativos y visionarios; hacen uso de las metáforas, el pensamiento analógico y la representación; rechazan lo tradicional y las estructuras rígidas; son lúdicos, fantasiosos e imaginativos por naturaleza. Les falta organización, estructura, claridad, rigor, lógica y método.

2-1-1-2 Dominancia doble: individuos con una preferencia primaria por las características de los cuadrantes B y C (límbico izquierdo y límbico derecho),imponen la razón sobre la realidad; desconfían de las emociones y la intuición; controlan sus ambientes y su propia personalidad; son organizados; se proponen realizar sus tareas de manera correcta y a tiempo; se distinguen por focalizar un solo aspecto a la vez; y por mantener el sentido de previsibilidad y seguridad. Les falta: apertura, fantasía y visión global; no saben que hacer frente a un imprevisto; no saben resumir un texto, ni describir una situación determinada.

(C) Rechazan la ambigüedad; son organizados y se proyectan hacia la acción; son receptivos, sensitivos y conciliatorios; su sensibilidad es importante para ayudar a otros a crecer y a cambiar; son empáticos y sociables; se distinguen por su capacidad de comunicación y de interacción social; son personas espirituales. A los individuos que tienen desarrollado el límbico derecho les falta: orden, rigor, conocimientos precisos, saber escuchar, control y dominio de sí mismo, organización; demuestran poca autonomía y perspectiva frente a la opinión ajena.

2-1-2-2 Dominancia simple: preferencia primaria por el cuadrante B (límbico izquierdo) imponen la razón sobre la realidad; desconfían de las emociones y la intuición; 
controlan sus ambientes y su propia personalidad; son organizados; se proponen realizar sus tareas de manera correcta y a tiempo; se distinguen por focalizar un solo aspecto a la vez; y por mantener el sentido de previsibilidad y seguridad. Les falta: apertura, fantasía y visión global; no saben que hacer frente a un imprevisto; no saben resumir un texto, ni describir una situación determinada.

1-2-1-2 Dominancia doble: preferencia primaria por los cuadrantes cortical izquierdo (A) y límbico derecho (C) se caracterizan por su facilidad para resolver problemas; dan importancia a la argumentación y la crítica sobre la experiencia personal y a los hechos sobre la intuición; son individuos fríos y arrogantes; sus soluciones, aunque lógicas, resultan demasiado lineales y poco creativas. Les falta: imaginación, creatividad, tienen pocas ideas personales y no expresan su sensibilidad; tienen pocas aptitudes para el arte, son demasiado individualistas.

(C) Rechazan la ambigüedad; son organizados y se proyectan hacia la acción; son receptivos, sensitivos y conciliatorios; su sensibilidad es importante para ayudar a otros a crecer y a cambiar; son empáticos y sociables; se distinguen por su capacidad de comunicación y de interacción social; son personas espirituales. A los individuos que tienen desarrollado el límbico derecho les falta: orden, rigor, conocimientos precisos, saber escuchar, control y dominio de sí mismo, organización; demuestran poca autonomía y perspectiva frente a la opinión ajena.

2-1-2-3 Dominancia simple: preferencia primaria por el cuadrante límbico izquierdo(B) imponen la razón sobre la realidad; desconfían de las emociones y la intuición; controlan sus ambientes y su propia personalidad; son organizados; se proponen realizar sus tareas de manera correcta y a tiempo; se distinguen por focalizar un solo aspecto a la vez; y por mantener el sentido de previsibilidad y seguridad. Les falta: apertura, fantasía y visión global; no saben que hacer frente a un imprevisto; no saben resumir un texto, ni describir una situación determinada.

1-2-3-2 Dominancia simple: preferencia primaria por el cuadrante cortical izquierdo (A) se caracterizan por su facilidad para resolver problemas; dan importancia a la argumentación y la crítica sobre la experiencia personal y a los hechos sobre la intuición; son individuos fríos y arrogantes; sus soluciones, aunque lógicas, resultan demasiado lineales y poco creativas.Les falta: imaginación, creatividad, tienen pocas ideas personales y no expresan su sensibilidad; tienen pocas aptitudes para el arte, son demasiado individualistas.

2-2-1-1 Dominancia doble: preferencia primaria por los cuadrantes límbico derecho (C) y cortical derecho (D). Rechazan la ambigüedad; son organizados y se proyectan hacia la acción; son receptivos, sensitivos y conciliatorios; su sensibilidad es importante para ayudar a otros a crecer y a cambiar; son empáticos y sociables; se distinguen por su capacidad de comunicación y de interacción social; son personas espirituales. A los individuos que tienen desarrollado el límbico derecho les falta: orden, rigor, conocimientos precisos, saber escuchar, control y dominio de sí mismo, organización; demuestran poca autonomía y perspectiva frente a la opinión ajena.

(D) se caracterizan por ser innovadores, creativos y visionarios; hacen uso de las metáforas, el pensamiento analógico y la representación; rechazan lo tradicional y las estructuras rígidas; son lúdicos, fantasiosos e imaginativos por naturaleza. Les falta organización, estructura, claridad, rigor, lógica y método.

2-1-1-1 Dominancia triple: preferencia primaria por los cuadrantes $\mathrm{B}, \mathrm{Cy} \mathrm{D}$, se refiere a ciertos perfiles que tienen un solo cuadrante que no es primario. Los individuos con este tipo de perfil son organizados, secuenciales, holísticos, intuitivos, idealistas, comunicadores y demuestran un buen manejo de sus emociones. Además, presentan el inconveniente de tomarse más tiempo para madurar, debido a las posiciones opuestas entre los cuadrantes.

2-1-2-1: Dominancia doble: preferencia primaria por los cuadrantes límbico derecho ( B) y cortical derecho ( D) imponen la razón sobre la realidad; desconfían de las emociones y la intuición; controlan sus ambientes y su propia personalidad; son organizados; se proponen realizar sus tareas de manera correcta y a tiempo; se distinguen por focalizar un solo aspecto a la vez; y por mantener el sentido de previsibilidad y seguridad. Les falta: apertura, fantasía y visión global; no saben que hacer frente a un imprevisto; no saben resumir un texto, ni describir una situación determinada.

(D) Se caracterizan por ser innovadores, creativos y visionarios; hacen uso de las metáforas, el pensamiento 
Tabla 5. Frecuencias tipos de dominancia de $\mathrm{V}$ semestre.

\begin{tabular}{ccc}
\hline Dominancia & Frecuencia absoluta & Frecuencia relativa \\
Simple & 16 & $53 \%$ \\
Doble & 08 & $27 \%$ \\
Triple & 01 & $03 \%$ \\
Sin dominancia & 05 & $17 \%$ \\
Total & 30 & $100 \%$ \\
\hline
\end{tabular}

Tabla 6. Perfiles resultantes y tipos de dominancia $X$ semestre

\begin{tabular}{cccc}
\hline PERFILES & TIPO DE DOMINANCIA & $\begin{array}{c}\text { FRECUENCIA } \\
\text { ABSOLUTA }\end{array}$ & $\begin{array}{c}\text { FRECUENCIA } \\
\text { RELATIVA }\end{array}$ \\
$1-2-2-2$ & Simple & 6 & $20 \%$ \\
$1-1-2-3$ & Doble & 2 & $7 \%$ \\
$1-2-1-2$ & Doble & 4 & $13 \%$ \\
$2-1-1-2$ & Doble & 3 & $10 \%$ \\
$1-1-1-2$ & Triple & 1 & $3 \%$ \\
$2-2-1-2$ & Simple & 1 & $3 \%$ \\
$2-2-2-2$ & Sin dominancia & 5 & $17 \%$ \\
$2-1-2-2$ & Simple & 4 & $13 \%$ \\
$1-1-2-2$ & Doble & 1 & $3 \%$ \\
$1-1-2-1$ & Triple & 1 & $7 \%$ \\
$2-2-1-1$ & Doble & 2 & $3 \%$ \\
Total & & 30 & $100 \%$ \\
\hline
\end{tabular}

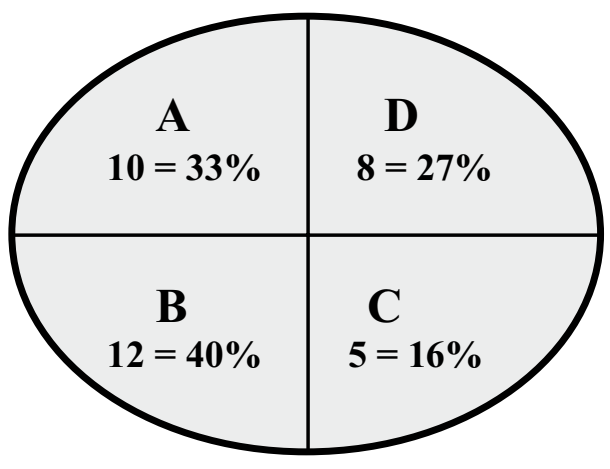

Figura 2. Dominancia por cuadrantes $V$ semestre

analógico y la representación; rechazan lo tradicional y las estructuras rígidas; son lúdicos, fantasiosos e imaginativos por naturaleza. Les falta organización, estructura, claridad, rigor, lógica y método (10), Tablas 5 y 6 , Figura 2.

\section{Caracterización de los perfiles resultantes}

1-2-2-2 Dominancia simple: indica una clara preferencia por el cuadrante A (cortical izquierdo). En este tipo de sujetos predominan la lógica y la razón. Se caracterizan por su facilidad para resolver problemas; dan importancia a la argumentación y la crítica sobre la experiencia personal y a los hechos sobre la intuición; son individuos fríos y arrogantes; sus soluciones, aunque lógicas, resultan demasiado lineales y poco creativas. Les falta: imaginación, creatividad, tienen pocas ideas personales y no expresan su sensibilidad; tienen pocas aptitudes para el arte, son demasiado individualistas.

1-1-2-3 Dominancia doble: preferencia primaria por los cuadrantes cortical izquierdo(A) y límbico izquierdo(B). Se caracterizan por su facilidad para 
resolver problemas; dan importancia a la argumentación y la crítica sobre la experiencia personal y a los hechos sobre la intuición; son individuos fríos y arrogantes; sus soluciones, aunque lógicas, resultan demasiado lineales y poco creativas. Les falta: imaginación, creatividad, tienen pocas ideas personales y no expresan su sensibilidad; tienen pocas aptitudes para el arte, son demasiado individualistas. (B) imponen la razón sobre la realidad; desconfían de las emociones y la intuición; controlan sus ambientes y su propia personalidad; son organizados; se proponen realizar sus tareas de manera correcta y a tiempo; se distinguen por focalizar un solo aspecto a la vez; y por mantener el sentido de previsibilidad y seguridad. Les falta: apertura, fantasía y visión global; no saben que hacer frente a un imprevisto; no saben resumir un texto, ni describir una situación determinada.

1-2-1-2 Dominancia doble: preferencia primaria por los cuadrantes A ( cortical izquierdo) y C ( límbico derecho) Se caracterizan por su facilidad para resolver problemas; dan importancia a la argumentación y la crítica sobre la experiencia personal y a los hechos sobre la intuición; son individuos fríos y arrogantes; sus soluciones, aunque lógicas, resultan demasiado lineales y poco creativas. Les falta: imaginación, creatividad, tienen pocas ideas personales y no expresan su sensibilidad; tienen pocas aptitudes para el arte, son demasiado individualistas. (C) Rechazan la ambigüedad; son organizados y se proyectan hacia la acción; son receptivos, sensitivos y conciliatorios; su sensibilidad es importante para ayudar a otros a crecer y a cambiar; son empáticos y sociables; se distinguen por su capacidad de comunicación y de interacción social; son personas espirituales. A los individuos que tienen desarrollado el límbico derecho les falta: orden, rigor, conocimientos precisos, saber escuchar, control y dominio de si mismo, organización; demuestran poca autonomía y perspectiva frente a la opinión ajena

2-1-1-2 Dominancia doble: los individuos con una preferencia primaria por las características de los cuadrantes B y C), imponen la razón sobre la realidad; desconfían de las emociones y la intuición; controlan sus ambientes y su propia personalidad; son organizados; se proponen realizar sus tareas de manera correcta y a tiempo; se distinguen por focalizar un solo aspecto a la vez; y por mantener el sentido de previsibilidad y seguridad. Les falta: apertura, fantasía y visión global; no saben que hacer frente a un imprevisto; no saben resumir un texto, ni describir una situación determinada. (C) Rechazan la ambigüedad; son organizados y se proyectan hacia la acción; son receptivos, sensitivos y conciliatorios; su sensibilidad es importante para ayudar a otros a crecer y a cambiar; son empáticos y sociables; se distinguen por su capacidad de comunicación y de interacción social; son personas espirituales. A los individuos que tienen desarrollado el límbico derecho les falta: orden, rigor, conocimientos precisos, saber escuchar, control y dominio de si mismo, organización; demuestran poca autonomía y perspectiva frente a la opinión ajena

1-1-1-2 Dominancia triple: los individuos con este tipo de perfil son lógico-analíticos, organizados, secuenciales, comunicadores y demuestran un buen manejo de sus emociones. Sin embargo, presentan el inconveniente de tomarse más tiempo para madurar, debido a las posiciones opuestas entre los cuadrantes.

2-2-1-2 Dominancia simple: los individuos que demuestran este perfil demuestran una clara preferencia por el cuadrante límbico derecho ( C) Rechazan la ambigüedad; son organizados y se proyectan hacia la acción; son receptivos, sensitivos y conciliatorios; su sensibilidad es importante para ayudar a otros a crecer y a cambiar; son empáticos y sociables; se distinguen por su capacidad de comunicación y de interacción social; son personas espirituales. A los individuos que tienen desarrollado el límbico derecho les falta: orden, rigor, conocimientos precisos, saber escuchar, control y dominio de si mismo, organización; demuestran poca autonomía y perspectiva frente a la opinión ajena

2-2-2-2 Sin Dominancia: es un perfil promedio que indica la existencia de un desarrollo intermedio de los cuatro cuadrantes, siendo necesarios algunos procesos cognitivos y metodológicos para potenciar el cerebro total.

2-1-2-2 Dominancia simple: los individuos con este perfil demuestran preferencia por el cuadrante límbico izquierdo ( B) imponen la razón sobre la realidad; desconfían de las emociones y la intuición; controlan sus ambientes y su propia personalidad; son organizados; se proponen realizar sus tareas de manera correcta y a tiempo; se distinguen por focalizar un solo aspecto a la vez; y por mantener el sentido de previsibilidad y seguridad. Les falta: 
Tabla 7. Frecuencias tipos de dominancia de $\mathrm{X}$ semestre.

\begin{tabular}{ccc}
\hline Dominancia & Frecuencia absoluta & Frecuencia relativa \\
Simple & 11 & $37 \%$ \\
Doble & 12 & $39 \%$ \\
Triple & 2 & $7 \%$ \\
Sin dominancia & 5 & $17 \%$ \\
Total & 30 & $100 \%$ \\
\hline
\end{tabular}

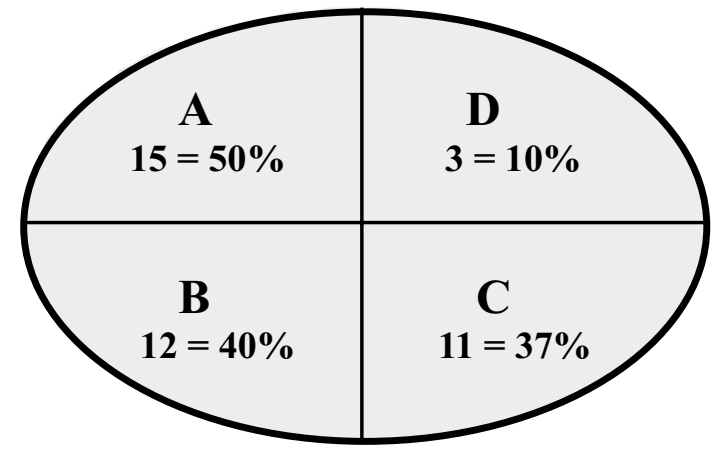

Figura 3. Dominancia por cuadrante $X$ semestre.

apertura, fantasía y visión global; no saben que hacer frente a un imprevisto; no saben resumir un texto, ni describir una situación determinada.

1-1-2-2 Dominancia doble: son individuos que demuestran una clara preferencia por las características del cuadrante A y B (cortical izquierdo y límbico izquierdo) y demuestran una clara preferencia por las características del cuadrante A (cortical izquierdo); se caracterizan por su facilidad para resolver problemas; dan importancia a la argumentación y la crítica sobre la experiencia personal y a los hechos sobre la intuición; son individuos fríos y arrogantes; sus soluciones, aunque lógicas, resultan demasiado lineales y poco creativas. Les falta: imaginación, creatividad, tienen pocas ideas personales y no expresan su sensibilidad; tienen pocas aptitudes para el arte, son demasiado individualistas (B) imponen la razón sobre la realidad; desconfían de las emociones y la intuición; controlan sus ambientes y su propia personalidad; son organizados; se proponen realizar sus tareas de manera correcta y a tiempo; se distinguen por focalizar un solo aspecto a la vez; y por mantener el sentido de previsibilidad y seguridad. Les falta: apertura, fantasía y visión global; no saben que hacer frente a un imprevisto; no saben resumir un texto, ni describir una situación determinada.
1-1-2-1 Dominancia triple: los individuos con este tipo de perfil son lógico-analíticos, organizados, secuenciales, holísticos, intuitivos, sintetizador-integradores e idealistas. Sin embargo, presentan el inconveniente de tomarse más tiempo para madurar, debido a las posiciones opuestas.

2-2-1-1 Dominancia doble: preferencia primaria por los cuadrantes límbico derecho (C) y cortical derecho (D). Rechazan la ambigüedad; son organizados y se proyectan hacia la acción; son receptivos, sensitivos y conciliatorios; su sensibilidad es importante para ayudar a otros a crecer y a cambiar; son empáticos y sociables; se distinguen por su capacidad de comunicación y de interacción social; son personas espirituales. A los individuos que tienen desarrollado el límbico derecho les falta: orden, rigor, conocimientos precisos, saber escuchar, control y dominio de sí mismo, organización; demuestran poca autonomía y perspectiva frente a la opinión ajena.

(D) Se caracterizan por ser innovadores, creativos y visionarios; hacen uso de las metáforas, el pensamiento analógico y la representación; rechazan lo tradicional y las estructuras rígidas; son lúdicos, fantasiosos e imaginativos por naturaleza. Les falta organización, estructura, claridad, rigor, lógica y método, Tabla 7 y Figura 3 (10).

Como se puede observar, no hay diferencias estadísticamente significativas en cuanto a los factores A-B-C y D finales, entre los estudiantes de primero, quinto y décimo semestres.

Dado que los datos totales se ajustaron a una distribución normal y su varianza fue homogénea, se opta por utilizar la prueba One Way Anova. Los resultados se presentan en la Tabla 8. La hipótesis de nulidad de esta prueba indica que las medianas de los grupos son iguales (no hay diferencias). 


\section{Estudio estadístico para la comparación de los perfiles de dominancia cerebral de los estudiantes de primero, quinto y décimo semestres.}

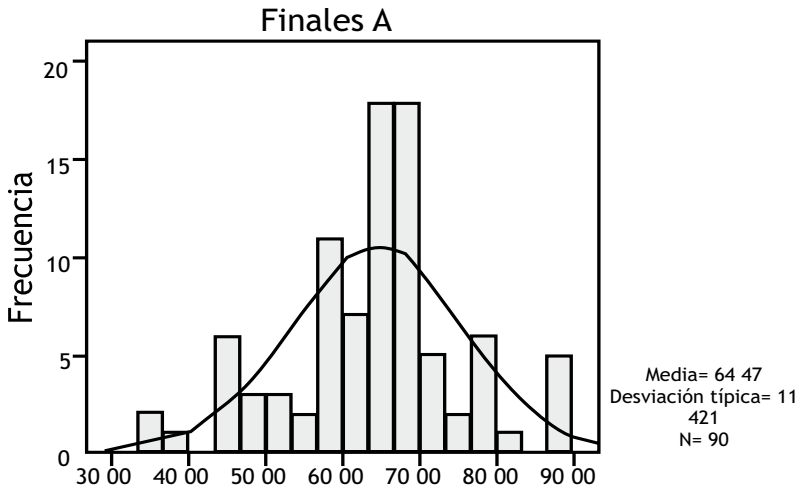

Figura 4. Resultados finales cuadrante A. Distribución global de los datos en Cuadrante A: Se observa una distribución sesgada levemente a la izquierda con ajuste normal (Kolmogorov Smirnov $p=0.200$ )

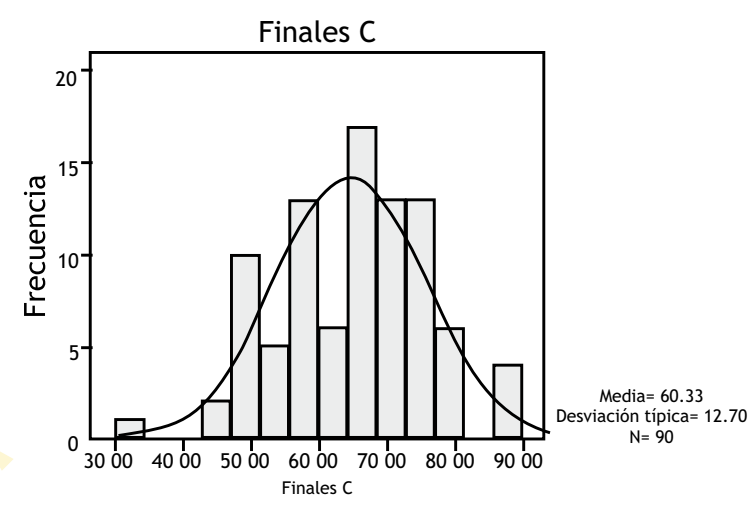

Figura 6. Resultados finales cuadrante C. Distribución global de los datos en Cuadrante A: Se observa una distribución sesgada levemente a la izquierda con ajuste normal (Kolmogorov Smirnov $p=0.202$ )

\section{Discusión}

Es importante tener en cuenta las características de cada cuadrante y relacionarlas con los datos obtenidos en la investigación. El cuadrante A (Cortical izquierdo), se caracteriza por el rigor del pensamiento analítico y cuantitativo, la reflexión crítica, las relaciones lógicas que ayudan a explicar la realidad que se vive. Como se observa en la figura 1, 2 y 3 el $47 \%$, el $33 \%$ y el $50 \%$ de los estudiantes de I, $\mathrm{V}$ y X semestres respectivamente, presentan dominancia en el cuadrante $A$, lo que es compatible por la carrera que estudian.

El cuadrante B (Límbico izquierdo), se caracteriza por un estilo de pensamiento secuencial, organizado y planificado. Las estrategias que conforman este cuadrante

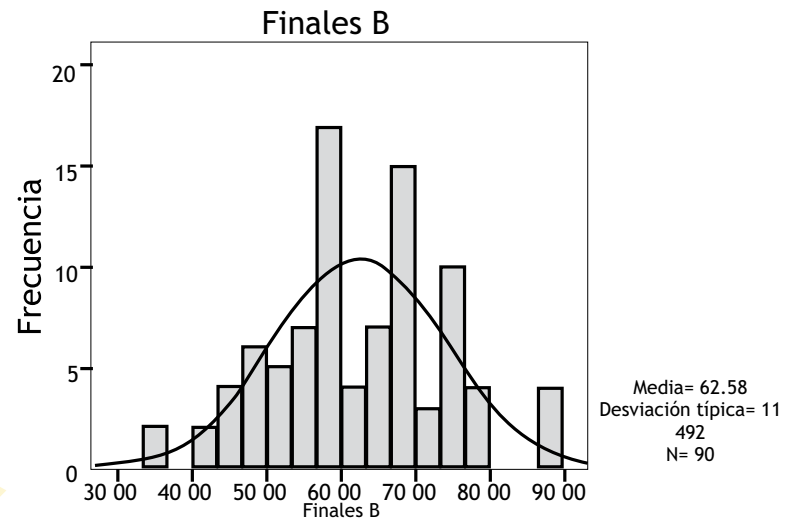

Figura 5. Resultados finales cuadrante B. Distribución global de los datos en Cuadrante B: Se observa una distribución sesgada levemente a la izquierda con ajuste normal (Kolmogorov Smirnov $p=0.200$ )

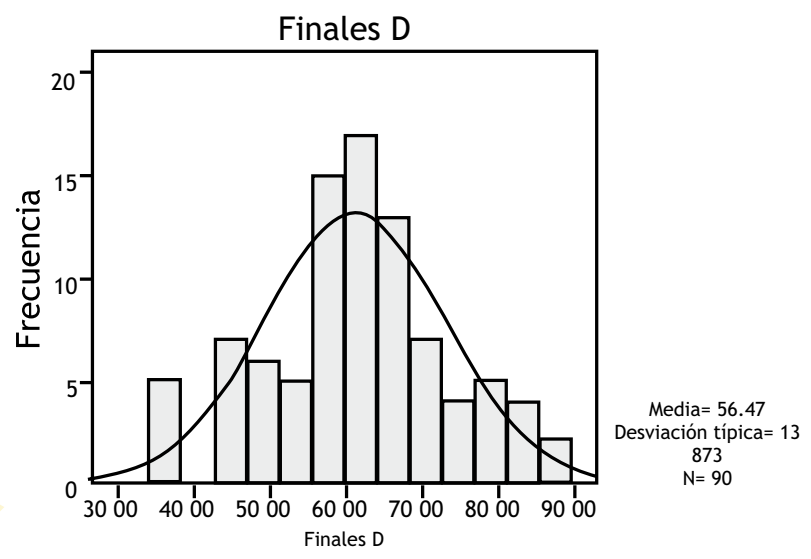

Figura 7. Resultados finales cuadrante D. Distribución global de los datos en Cuadrante D: Se observa una distribución sesgada levemente a la izquierda con ajuste normal (Kolmogorov Smirnov $p=0.200$ )

son definidas como operacionales, dirigidas especialmente a la ejecución de acciones, previamente diseñadas para el manejo de múltiples situaciones relacionadas con grupos de individuos y organizaciones. Este cuadrante no desarrolla la criticidad, sino que enfatiza en la tradición y planificación normativa.

Lo importante no es la búsqueda de alternativas distintas o el procesamiento de ideas con visión estratégica, sino que lo primordial es administrar recursos, establecer prioridades, realizar seguimiento a los procedimientos que se están realizando, supervisar desempeños y evaluar resultados, con miras al cumplimiento de metas, con eficiencia y eficacia. Respecto a los resultados obtenidos se infiere que el $43 \%$, el $40 \%$ y el $40 \%$ de los estudiantes 
Tabla 8. Análisis estadísticos según One Way Anova.

ANOVA

\begin{tabular}{ll|r|r|r|r|r}
\hline & \multicolumn{1}{c|}{$\begin{array}{c}\text { Suma de } \\
\text { cuadrados }\end{array}$} & gl & $\begin{array}{c}\text { Media } \\
\text { cuadrática }\end{array}$ & \multicolumn{1}{c|}{$\mathrm{F}$} & \multicolumn{1}{c}{ Sig. } \\
\hline Finales A & Inter-grupos & 173.867 & 2 & 86.933 & .661 & .519 \\
& Intra-grupos & 11434.533 & 87 & 131.431 & & \\
& Total & 11608.400 & 89 & & & .603 \\
Finales B & Inter-grupos & 184.089 & 2 & 92.044 & .692 & .413 \\
& Intra-grupos & 11569.867 & 87 & 132.987 & & \\
& Total & 11753.956 & 89 & & & \\
Finales C & Inter-grupos & 288.800 & 2 & 144.400 & .893 & .273 \\
& Intra-grupos & 14065.200 & 87 & 161.669 & & \\
& Total & 14354.000 & 89 & & & \\
\hline \multirow{2}{*}{ Finales D } & Inter-grupos & 504.267 & 2 & 252.133 & 1.320 & \\
& Intra-grupos & 16624.133 & 87 & 191.082 & & \\
& Total & 17128.400 & 89 & & & \\
\hline
\end{tabular}

gl: grados de libertad asociados a cada suma de cuadrados

F: estadístico que refleja el grado de parecido existente entre las medias que se están comparando.

Sig: nivel crítico o nivel de significación observado.

de I, Vy X semestres, respectivamente tienen dominancia en este cuadrante.

El cuadrante C (límbico derecho), es especialmente comunicativo y expresivo, con clara tendencia del individuo de involucrarse en relaciones interpersonales de cooperación y amistad y en proyectos comunitarios de asistencia y orientación social. Los estudiantes encuestados de I, V y X semestres respectivamente presentan un $33 \%$, $16 \%$ y $37 \%$ de dominancia de este cuadrante,

El cuadrante D (Cortical derecho), es considerado "el cuadrante de la creatividad", ya que es el disparador de situaciones novedosas, no convencionales, realizadas y planeadas conscientemente por medio de la imaginación. Es el motor del desarrollo de proyectos visionarios y del diseño de una planeación estratégica. De los resultados obtenidos se puede deducir que el 17\%, el $27 \%$ y el $10 \%$ de los estudiantes de I, $\mathrm{V}$ y X semestres respectivamente tienen dominancia en este cuadrante, lo cual refleja la poca preferencia por éste, situación demasiado desventajosa para el desarrollo del potencial creativo individual y social. Estos resultados sugieren la realización de estrategias que permitan el desarrollo de dicho cuadrante.

En las Tablas 3, 5 y 7 se observa que el 53\%, 53\% y 37\% de los estudiantes de I, V y X semestres respectivamente, poseen dominancia simple, es decir dominancia primaria en un cuadrante; el resto es secundaria o terciaria para los otros tres cuadrantes, distribución que permite identificar el patrón cultural de la población. Los estudiantes con dominancia simple se caracterizan por tener menos conflictos internos y tomar decisiones armónicas y predecibles. Sin embargo, su capacidad para interactuar es reducida, así como su capacidad de independencia creativa (7).

El 33\%, el 27\% y el 39\% de los estudiantes de I, V y X semestres, respectivamente presentan dominancia doble, es decir exhiben más de una preferencia primaria. Los estudiantes que exhiben la preferencia doble (A y B), amplía la calidad del pensamiento de los individuos, mientras que el conjunto primario ( $\mathrm{C}$ y $\mathrm{D})$, al combinar sensibilidad con innovación, amplía las condiciones visionarias e innovadoras de $\mathrm{D}$.

Los estudiantes que presentan doble dominancia cerebral y límbica tienen la ventaja de que pueden entender el pensamiento no lineal y verbalizarlo; también pueden ir del pensamiento racional, basado en hechos, a modalidades vivénciales; tienen mayor capacidad para interactuar y pueden hacer su pensamiento más accesible. Una de las desventajas que tienen las personas con doble dominancia del tipo A-D y B-C, es que poseen dos opciones bastante diferentes para actuar. Lo cual hace que la toma de decisiones pueda tomarle mucho tiempo. 
Los perfiles de triple dominancia (1-1-2-1) tienen un sólo cuadrante que no es primario. Los sujetos con este tipo de perfil tienen habilidades lingüísticas, por cuanto les es fácil interactuar libremente con los otros cuadrantes, dejando claro que, por lo general, el cuadrante no primario nunca llega a ser terciario. La desventaja de los perfiles de triple dominancia es que pueden llevar más tiempo para madurar, debido a las mismas posiciones opuestas que se van a encontrar entre los cuadrantes, tal y como sucede con los cuadrantes diagonalmente opuestos (7). De acuerdo con los resultados obtenidos el 7\%, el 3\% y el 7\% de los estudiantes de I, V, y X semestres respectivamente presentan triple dominancia es decir exhiben dominancia en tres cuadrantes.

Con relación a la comparación del perfil de dominancia de los estudiantes de primero, quinto y décimo semestres se observa que: no todas las variables a comparar presentaron un comportamiento ajustado a la normal, por ello, se hace necesario implementar pruebas no paramétricas para el análisis de datos.

Los datos finales se ajustaron en su totalidad a una distribución normal y su varianza fue homogénea, esto llevó a utilizar la prueba One Way Anova. La hipótesis de nulidad de esta prueba indica que las medianas de los grupos son iguales (no hay diferencias). Por ello, la alternativa de análisis es la prueba de la mediana.

Los resultados arrojados por la investigación permiten anotar que la mayoría de los estudiantes presentan un desarrollo apreciable en los cuadrantes A, B, es decir, presentan un pensamiento analítico, cuantitativo, administrativo, y procedimental. Se observa poca dominancia en el cuadrante cortical derecho (D), lo que implica una carencia de pensamiento relacionada con la creatividad, la visión holística, la imaginación, la prospectiva y la heurística, necesarias en la óptima potenciación de las capacidades del cerebro total, lo que podría generar en un futuro vacíos en la formación del futuro profesional. Estas son incidencias que exigen replanteamiento y transformación de los métodos educativos que se implementan en el aula de clase, los cuales deben favorecer el desarrollo de los cuatro cuadrantes en cada estudiante.

Uno o más de los cuadrantes por efectos de predisposiciones genéticas se vuelven naturalmente dominantes, esto es, se constituyen en los estilos de procesamiento preferidos por los individuos. Los resultados evidencian cambios poco significativos entre los estudiantes de primero, quinto y décimo semestres, en cuanto a sus puntuaciones de dominancia cerebral. Diferentes fuentes teóricas han indicado que múltiples capacidades cognoscitivas y conductuales tienen un origen génico Por ejemplo, la habilidad matemática está caracterizada por un interesante desarrollo de la corteza parietal izquierda $(6,11,12)$.

También se ha establecido que durante el proceso embrionario, el factor de crecimiento nervioso (FCN) facilita el desarrollo de neuronas sensoriales especializadas del ectodermo, que explicarían el avance de esta zona del cerebro. El factor neurotrópico de crecimiento derivado del cerebro y el factor de crecimiento derivado de células de la glia serían protagonistas importantes durante el desarrollo biológico de regiones especializadas del cerebro $(6,11,12)$.

Los resultados de este estudio permiten verificar la estabilidad de los patrones de dominancia cerebral a lo largo del desarrollo humano; la cual podría verse explicada por factores biológicos genéticamente privilegiados que valdría la pena seguir estudiando. Además, uno de los factores ambientales responsable de la estabilidad de los patrones de dominancia cerebral en nuestro estudio es la educación, sector en donde se hace un análisis crítico e histórico y se concluye que: las herramientas didácticas no facilitan el desarrollo de competencias propositivas elementales para propiciar una actitud creativa frente a la toma de decisiones y la solución de problemas.

Además, los escenarios de aprendizaje se encuentran poco enriquecidos, lo que incide en la motivación demostrada por el estudiante en cuanto a desarrollo de habilidades por encima del promedio de las personas. Las relaciones entre los actores de la escena educativa (estudiantes, maestros, administrativos) no facilita cadenas de comunicación de la información efectiva y los currículos atomizados y la tendencia a darle más importancia a la modalidad presencial que al estudio independiente, hace que los estudiantes sean dependientes de la opinión de otros (docentes y libros) inhibiendo posibilidades de desarrollo de estilos cognoscitivos propios.

Otro factor incidente es el contexto cultural, donde es escaso el apoyo familiar en la educación, así como los costos elevados de la misma, la accesibilidad al sistema educativo y los recursos, entre otros aspectos. Igualmente, 
un factor recurrente es el individualismo (característica propia de ciertos sectores culturales de Colombia) hace que los estudiantes adopten puntos de vista no sustentados por la opinión de otros, inhibiendo así la posibilidad de enriquecer los saberes personales y profesionales frente a diversos tópicos y situaciones presentadas.

No se evidenciaron diferencias estadísticamente significativas en cuanto a desarrollo de pensamiento holístico, global, integrador, sintético, creativo y ello es atribuible a aspectos ambientales, sociales y educativos que inhiben la posibilidad de los jóvenes de ser creativos.

Como docentes investigadoras y con base en los resultados obtenidos, nos permitimos sugerir como proyección a esta investigación, diseñar y aplicar estrategias que permitan el desarrollo de los dos hemisferios, teniendo en cuenta que un individuo con perfil de dominancia cuádruple posee la ventaja de moverse entre uno y todos los cuadrantes, lo cual le facilita una visión balanceada de diferentes situaciones; igualmente, comunicarse con facilidad con personas que demuestran predominio en uno o más cuadrantes y que puedan actuar como intérpretes entre individuos que tienen dominancias cerebrales distintas (7). NO

\section{Referencias}

1. Herrmann N. The whole brain business. New York: N. Y. Ed. McGraw - Hill; 1995.

2. Sperry R. Lateral specialization of cerebral function in the surgically separated hemispheres. In F.J. New York : Academic Press; 1973.

3. MacLean P. The triune brain evolution. New York: Plenun Press; 1990.

4. Gardner H. Estructuras de la mente. La teoría de las inteligencias múltiples. Colombia: Fondo de Cultura Económica; 1997.

5. Gardié O. Estilos de pensamiento de los docentes del Instituto Pedagógico de Maracay: configuración y perfiles derivados del modelo de Cerebro Total de Herrmann. Caracas: Universidad Pedagógica Libertador Colecciones CIEAPRO No. 1. 1994.

6. Salas R. Cómo hacer una enseñanza más de acuerdo con la manera como aprende el cerebro. En: Neurociencia y Educación. Forfill Valparaíso, Chile. 2003

7. Jiménez CA. Cerebro creativo y lúdico. Hacia la construcción de una nueva didáctica para el siglo XXI. Cooperativa Editorial Magisterio: Magisterio 2000.

8. Herrmann SL. The creative brain. Búfalo. Brain books. 1989.

9. Gardié O. Diagnóstico integral de dominancia cerebral. Venezuela: Universidad Pedagógica Libertador; 2001.

10. Velásquez, Remolina, Calle. El cerebro . Un mundo de posibilidades para el aprendizaje. Bogotá: Universidad Colegio Mayor de Cundinamarca; 2006.

11. Eric J. Cerebro y aprendizaje. Competencias e implicaciones educativas. Nancea S.A., Madrid. 2004

12. Gardner H. La educación de la mente y el conocimiento de las disciplinas. Paidós, Iberica, S.A., Barcelona. 2000. 